Article

\title{
Use of the Standardized Precipitation Evapotranspiration Index (SPEI) to Characterize the Drying Trend in Southwest China from 1982-2012
}

\author{
Xing Li, Binbin He *, Xingwen Quan, Zhanmang Liao and Xiaojing Bai \\ School of Resources and Environment, University of Electronic Science and Technology of China, \\ No. 2006, Xiyuan Ave, West Hi-Tech Zone, Chengdu 611731, China; E-Mails: zxwlxty@ 163.com (X.L.); \\ quanxw7@gmail.com (X.Q.); dajuzidesky@163.com (Z.L.); baixiaojing1219@126.com (X.B.) \\ * Author to whom correspondence should be addressed; E-Mail: binbinhe@ uestc.edu.cn; \\ Tel.: +86-28-6183-1586.
}

Academic Editors: Xuepeng Zhao, Wenze Yang, Alfredo R. Huete and Prasad S. Thenkabail

Received: 14 July 2015 / Accepted: 18 August 2015 / Published: 24 August 2015

\begin{abstract}
In this study, the Standardized Precipitation Evaporation Index (SPEI) was applied to characterize the drought conditions in Southwest China from 1982-2012. The SPEI was calculated by precipitation and temperature data for various accumulation periods. Based on the SPEI, the multi-scale patterns, the trend, and the spatio-temporal extent of drought were evaluated, respectively. The results explicitly showed a drying trend of Southwest China. The mean SPEI values at five time scales all decreased significantly. Some moderate and severe droughts were captured after 2005 and the droughts were even getting aggravated. By examining the spatio-temporal extent, the aggravating condition of drought was further revealed. To investigate the performance of SPEI, correlation analysis was conducted between SPEI and two remotely sensed drought indices: Soil Moisture Condition Index (SMCI) and Vegetation Condition Index (VCI). The comparison was also conducted with the Standardized Precipitation Index (SPI). The results showed that for both SMCI and VCI, the SPI and SPEI had approximate correlations with them. The SPEI could better monitor the soil moisture than the SPI in months with significant increase of temperature. The correlations between the VCI and SPI/SPEI were lower; nevertheless, the SPEI was slightly superior to the SPI.
\end{abstract}


Keywords: drought; Standardized Precipitation Evaporation Index (SPEI); Standardized Precipitation Index (SPI); Vegetation Condition Index (VCI); Soil Moisture Condition Index (SMCI); trend analysis; Southwest China

\section{Introduction}

In the context of global warming, extreme weather and climatological events such as flood and drought seem to be occurring more frequently. Especially the drought, commonly defined as water deficits during a determined period [1], is one of the costliest and most widespread natural disasters with negative impacts on agriculture, water resources, natural ecosystems, and society activities [2-4]. Droughts are often divided into four categories according to the American Meteorological Society [5-7]: (1) Meteorological drought is defined as a lack of precipitation over a region for a period of time; (2) Agricultural drought refers to a period with soil moisture deficiency, which leads to reduced crop production and plant growth; (3) Hydrological drought occurs with inadequate surface and subsurface water resources supply; (4) Socioeconomic drought is associated with insufficient water resources supply to meet the economic demand with the above three types of drought. Meteorological drought is accompanied by below-normal precipitation and above-normal temperature, and it normally precedes and triggers other types of droughts $[8,9]$. Therefore, it is necessary to monitor the meteorological drought timely and provide early warning and risk management of water resources and agricultural production [9].

To monitor the drought, the duration, magnitude, and spatial extent of the drought need to be evaluated. These characteristics are useful for providing an objective and quantitative assessment of drought severity, and are commonly presented by use of the drought indices, which are constructed based on different climatic and hydrological variables that can reflect different aspects of drought [2,10-12]. In the past decades, scientists have made great efforts to develop different drought indices, and their advantages and disadvantages have been extensively discussed [1,6-8,13-15]. The Palmer Drought Severity Index (PDSI) [16] was a landmark in the development of drought indices. It takes antecedent precipitation, moisture supply, and moisture demand into account, has been frequently used to quantify dryness and wetness conditions. However, it cannot be flexibly analyzed at different temporal scales to evaluate the different types of drought [13]. To address temporal scale problems present in the PDSI, McKee et al. [17] demonstrated the multi-scalar nature of droughts and developed the Standardized Precipitation Index (SPI) by means of a precipitation probabilistic approach. The SPI is calculated by fitting a probability density function to a given frequency distribution of historical precipitation and then the probabilities are transformed into a standardized normal distribution with a mean of zero and variance of one. The main advantages of the SPI include the simplicity of calculation and its multi-scalar characteristic. The latter means it can be analyzed at different temporal scales (e.g., 1, 3, 6 or more longer months) according to users' need to monitor the different types of drought including the meteorological, agricultural, and hydrological drought $[1,9,17]$. Nevertheless, the main criticism of the SPI is that its calculation is only on basis of precipitation data and without consideration of the effect of evapotranspiration $[1,10,17]$. The Standardized Precipitation Evapotranspiration Index (SPEI), proposed by Vicente-Serrano et al. [18], is considered to be a suitable alternative for the SPI and PDSI. Mathematically, 
the SPEI is similar to the SPI, but it incorporates temperature data for the calculation of potential evapotranspiration. Therefore, it combines the sensitivity of the PDSI to the changes in evapotranspiration demand (caused by air temperature fluctuations and trends) with the multi-temporal nature of the SPI $[8,19]$.

In the past decades, China experienced an increasing trend in drought events and large areas have suffered sustained and severe droughts at different time scales [20,21]. The situation has further deteriorated since the 1990s. Nationwide droughts occur almost every year, causing losses of agricultural production and lack of water resources supply [22-24]. Especially in Southwest China, where the monthly, annual, and interannual variations in precipitation and temperature are significant, the drought has become one of main natural disasters. It is reported that regional mean annual precipitation of Southwest China decreases by $11.4 \mathrm{~mm}$ per decade and experiences enhanced precipitation extremes in the past 60 years [25]. The droughts with different duration and severity have frequently hit in the year of 2006, 2009, 2010, and 2012. During the summer of 2006, Sichuan Province and Chongqing Municipality, both in Southwest China, experienced their most severe drought during the last 50 years. The average temperature of August in some regions exceeded $40{ }^{\circ} \mathrm{C}$ with concurrent decrease of precipitation [20,26]. In spring 2010, large areas of Southwest China were hit by a long-lasting and severe drought. The drought started in autumn of 2009 and sustained until April 2010 and was considered to be a "once-in-a-century" drought $[27,28]$. It led to a great reduction in supply of drinking water to local inhabitants and had destructive effects on agricultural production, which caused substantial ecological losses and adverse socioeconomic impacts [20,27,28].

The below-normal precipitation is a trigger factor of these severe droughts, whereas the increasing temperature can usually aggravate the droughts. Especially in recent years, many droughts started in precipitation deficit and were deteriorated by high temperature [20,29]. Therefore, to monitor and quantify the drought in Southwest China, the drought index needs to be incorporated with the temperature information. In this study, our first objective is to provide a comprehensive analysis of the drought conditions in Southwest China during the period 1982-2012. Based on the SPEI series for various time lags, the multi-scale patterns, the trend, and the spatio-temporal extent of drought are successively analyzed. Since the link between precipitation, vegetation growth, and soil moisture is widely recognized $[1,30,31]$, our second objective is to provide robust insights into the performance of SPEI. In this case, the correlation analysis between SPEI and two remotely sensed drought indices (one is for monitoring the soil moisture and the other is for monitoring the vegetation drought) is performed, respectively. In addition, the comparison is conducted with the SPI which does not take the temperature into account.

\section{Data and Methods}

\subsection{Study Area}

The study area is situated in the southwestern of China, and consists of three provinces: Yunnan, Guizhou, and Sichuan, and a municipality, Chongqing, with an area about $1.13 \times 10^{6} \mathrm{~km}^{2}$ (Figure 1). The study region covers the southeastern Tibetan Plateau, most of the Sichuan Basin, and the Yunnan-Guizhou Plateau, with different landforms and complicated topography [27]. The Southwest China has relatively 
abundant water resources and it is the source and main runoff-generation area of many large rivers, such as the Yangtze River [32], the Yellow River, and the Pearl River, etc. The climate here belongs to the subtropical monsoon climate with a warm and humid condition. Annual precipitation is generally above $900 \mathrm{~mm}$ but unevenly distributed in months, with more than $85 \%$ in rainy season (April-October). Besides, the spatial distribution of precipitation is also uneven due to the complicated topography and a general decreasing trend is found from east and south to northwest regions [33]. A recent study showed that the changing trends of precipitation extremes were also not spatially uniform [34].

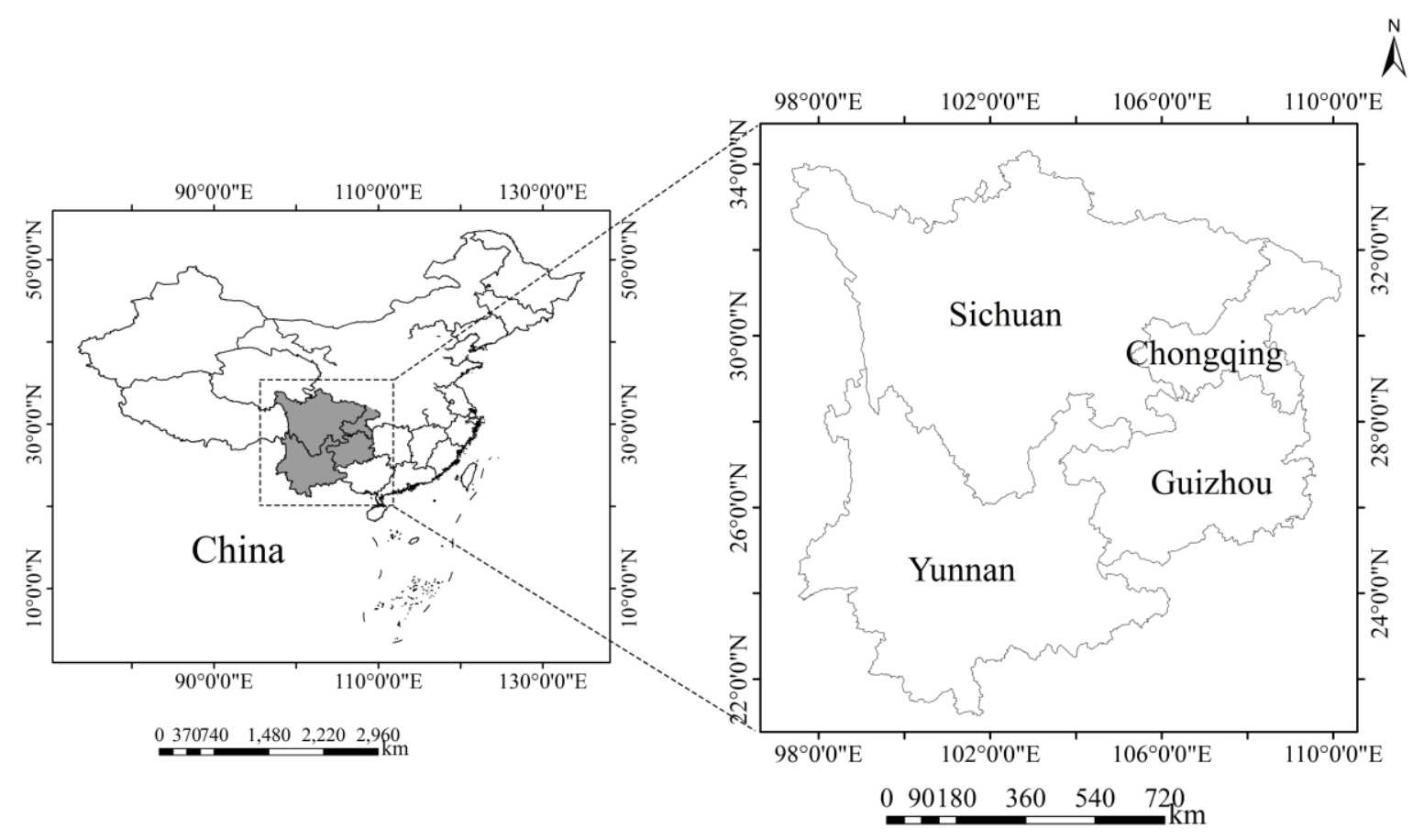

Figure 1. Location of the study area. That consists of three provinces: Yunnan, Guizhou, and Sichuan, and a municipality, Chongqing.

In recent years, with substantial reduction of precipitation and constant increase of temperature, the drought occurs frequently in Southwest China. It is reported that these severe droughts have caused evident change in regional conditions of water and heat, reducing the supply of drinking water to the local inhabitants, disturbing the function of the vegetation service, and even leading to reduction of biodiversity and degradation of vegetation $[35,36]$. Therefore, to characterize the moisture condition of Southwest China is of great importance for risk management of water resources and agricultural production, and also benefits to provide an early warning for the protection of ecological environment.

\subsection{SPEI}

In this study, the SPEI was applied to monitor and quantify the drought in Southwest China, and further comparison was conducted with the SPI to test its performance. Since the focus of this study is on the SPEI, the detailed description about SPI is not stated here and please refer to [17]. The SPEI is considered as an improved drought index of the SPI that is especially suited to analyze the effect of global warming on drought conditions [37]. The calculation of the SPEI in this study follows the method mentioned in [18]. 
The SPEI is based on a climatic water balance which is determined by the difference between precipitation (P) and potential evapotranspiration (PET) for the month $i$ :

$$
D_{i}=P_{i}-P E T_{i}
$$

which provides a simple measure of the water surplus or deficit for the analyzed month. The PET is calculated following the Thornthwaite equation [38].

The calculated $D_{i}$ values are aggregated at different time scales, following the same procedure as that for the SPI. The difference $D_{i, j}^{k}$ in a given month $j$ and year $i$ depends on the chosen time scale, $k$. For example, the accumulated difference for one month in a particular year, $i$ with a 12-month time scale is calculated according to:

$$
\begin{gathered}
X_{i, j}^{k}=\sum_{l=13-k+j}^{12} D_{i-1, l}+\sum_{l=1}^{j} D_{i, l}, \text { if } j<k, \text { and } \\
X_{i, j}^{k}=\sum_{l=j-k+1}^{j} D_{i, l}, \text { if } j \geq k
\end{gathered}
$$

where $D_{i, l}$ is the P-PET difference in the $l$ th month of year $i$, in mm.

And then the log-logistic distribution is selected for standardizing the $D$ series to obtain the SPEI. The probability density function of log-logistic distributed variable is expressed as:

$$
f(x)=\frac{\beta}{\alpha}\left(\frac{x-\gamma}{\alpha}\right)^{\beta-1}\left[1+\left(\frac{x-\gamma}{\alpha}\right)^{\beta}\right]^{-2}
$$

where $\alpha, \beta$, and $\gamma$ are scale, shape, and origin parameters, respectively, for $D$ values in the range $(\gamma>\mathrm{D}<\infty)$.

Thus, the probability distribution function of the $D$ series is given by:

$$
F(x)=\left[1+\left(\frac{\alpha}{x-\gamma}\right)^{\beta}\right]^{-1}
$$

With $F(x)$ the SPEI can easily be obtained as the standardized values of $F(x)$. For example, following the classical approximation of Abramowitz and Stegun [39]:

$$
S P E I=W-\frac{C_{0}+C_{1} W+C_{2} W^{2}}{1+d_{1} W+d_{2} W^{2}+d_{3} W^{3}}
$$

where $W=\sqrt{-2 \operatorname{In}(p)}$ for $p \leq 0.5$ and $p$ is the probability of exceeding a determined $D$ value, $p=1-F(x)$. If $p>0.5, p$ is replaced by $1-p$ and the sign of the resultant SPEI is reversed. The constants are: $C_{0}=2.515517, C_{1}=0.802853, C_{2}=0.010328, d_{1}=1.432788, d_{2}=0.189269$, and $d_{3}=0.001308$. Positive values of SPEI indicate the above average moisture conditions while negative values indicate the drier conditions. A drought event is defined when the SPEI value is less than or equal to -1 in a certain period. The drought categories according to the SPEI values are presented in Table 1.

The SPEI and SPI were calculated from monthly precipitation and temperature data during the period 1982 to 2012, which were obtained from China Meteorological Data Sharing Service System of China Meteorological Administration [40]. Stations with missing data in any of the 31 years were removed and finally a total of 89 stations were remained in this study. 
Table 1. Categorization of dryness/wetness grade by the Standardized Precipitation Evaporation Index (SPEI).

\begin{tabular}{cc}
\hline Categories & SPEI Values \\
\hline Extreme drought & Less than -2.00 \\
Severe drought & -1.99 to -1.50 \\
Moderate drought & -1.49 to -1.00 \\
Near normal & -0.99 to 0.99 \\
Moderately wet & 1.00 to 1.49 \\
Severely wet & 1.50 to 1.99 \\
Extremely wet & More than 2.00 \\
\hline
\end{tabular}

\subsection{Remotely Sensed Drought Indices}

Remote sensing technique provides an unprecedented global coverage of surface characteristics which are logistically and economically impossible to obtain through ground-based observations [41-43]. To investigate the performance of SPEI, the correlations between SPEI and two remotely sensed drought indices were calculated. The analysis was also conducted with the SPI for the purpose of comparison.

\subsubsection{The Vegetation Condition Index (VCI)}

In this study, the Vegetation Condition Index (VCI) $[44,45]$ was used to characterize the drought impact on vegetation. The VCI is calculated based on the Normalized Difference Vegetation Index (NDVI), which is a widely used index for monitoring the vegetation growth condition [46] and has a near-linear relationship with Leaf Area Index (LAI), chlorophyll abundance, and Net Primary Production (NPP) [47,48]. The VCI is a relative value which indicates the greenness of each pixel relative to the average condition over the historical record at a given time [49]. The VCI allows detection of drought and measurement of the time of its onset and its intensity, duration, and impact on vegetation [7]. The applications of VCI in monitoring the agricultural drought have been reported in numerous researches [3,9,49-51].

$$
V C I=\left(N D V I-N D V I_{\min }\right) /\left(N D V I_{\max }-N D V I_{\min }\right)
$$

The VCI was derived by using the latest version of biweekly $8 \mathrm{~km}$ NDVI data (NDVI3g) from Advanced Very High Resolution Radiometer (AVHRR) satellite sensors by the Global Inventory Modeling and Mapping Studies (GIMMS) group at NASA Goddard Space Flight Center [52]. The datasets have been processed to account for orbital drift, sensor degradation, cloud cover, and aerosols, and are suitable for identifying long-term trends in vegetation activity [46,53-55]. The monthly NDVI was derived by applying the maximum value composite (MVC) method [56] from the two NDVI in each month. Pixels with average annual NDVI less than 0.1 were considered as non-vegetated areas and thus masked in our study.

\subsubsection{The Soil Moisture Condition Index (SMCI)}

The soil moisture is also essential and important for assessing agricultural droughts since it balances the fluxes of precipitation, evapotranspiration, and runoff [22,57,58]. In this study, the Soil Moisture Condition Index (SMCI) [9] represented the dry or wet conditions of soil was used. It was constructed 
similar to VCI by simply scaling the soil moisture from $0-1$ using the minimum and maximum soil moisture for each location [9]. The definition of SMCI is as follow:

$$
S M C I=\left(S M-S M_{\min }\right) /\left(S M_{\max }-S M_{\min }\right)
$$

The monthly soil moisture data from 1982 to 2010 were obtained from Global Land Data Assimilation System Version 2.0 (GLDAS-2) products, which were acquired as part of the mission of NASA's Earth Science Division and archived and distributed by the Goddard Earth Sciences (GES) Data and Information Services Center (DISC). The data were simulated from the Noah Model 3.3 at $0.25^{\circ} \times 0.25^{\circ}$ spatial resolution and generated through temporal averaging of the 3-hourly data [59]. Other parameters such as evaporation, soil temperature, and plant canopy surface water, etc. could also been obtained from this dataset. The inputs of the model included the meteorological forcing data set, land cover, land water mask, soil texture, and elevation. The land surface parameter data used in the model was upgraded, and more details please refer to (http://ldas.gsfc.nasa.gov/gldas/). There were four vertical levels for the production of soil moisture, and in this study we used the upper layer $(0-10 \mathrm{~cm})$ to derive the SMCI.

\subsection{Analysis}

The non-parametric Mann-Kendall (MK) test $[60,61]$ was applied to detect the drying or wetting trend of the study area based on SPEI. It does not require an assumption of normality in variance and is less sensitive to outliers compared with linear regression analysis [62]. Therefore, it is widely used to evaluate the significance of trends in time series [8,13,19,63,64].

The standardized $Z$ values obtained from MK test provide a convenient means for quantifying the trend and its significance. The details for computing the $Z$ values can be found in $[63,64]$. Positive values of $Z$ indicate increasing trends while negative $Z$ values show decreasing trends. Testing trends is done at the specific $\alpha$ significance level. When the significance levels are set at $0.001,0.01,0.05$, and 0.1 and $|Z|$ are $3.29,2.575,1.96$ and 1.645 , respectively.

In addition, to provide robust insights into the performance of SPEI, the Pearson correlation analysis was performed between the monthly SPI/SPEI and two remotely sensed drought indices at 1, 3, 6, 12, 24-month accumulation period, respectively. The correlation coefficients were obtained in the growing season (from April to October) from 1982-2012 for VCI and each month from 1982-2010 for SMCI. The remotely sensed index values were extracted according to the in situ meteorological station location. Prior to correlation analysis, the trend in both the SPEI time series and remotely sensed indices were removed by assuming a linear evolution in each monthly series.

\section{Results and Discussion}

\subsection{Multi-Scale Patterns of the Drought}

Following the aforementioned methodology, the monthly SPEI was calculated at 24 time scales for all stations during the period 1982 to 2012 . Then, these SPEI time series were averaged over all 89 stations to characterize the dry or wet conditions in the whole Southwest China. 


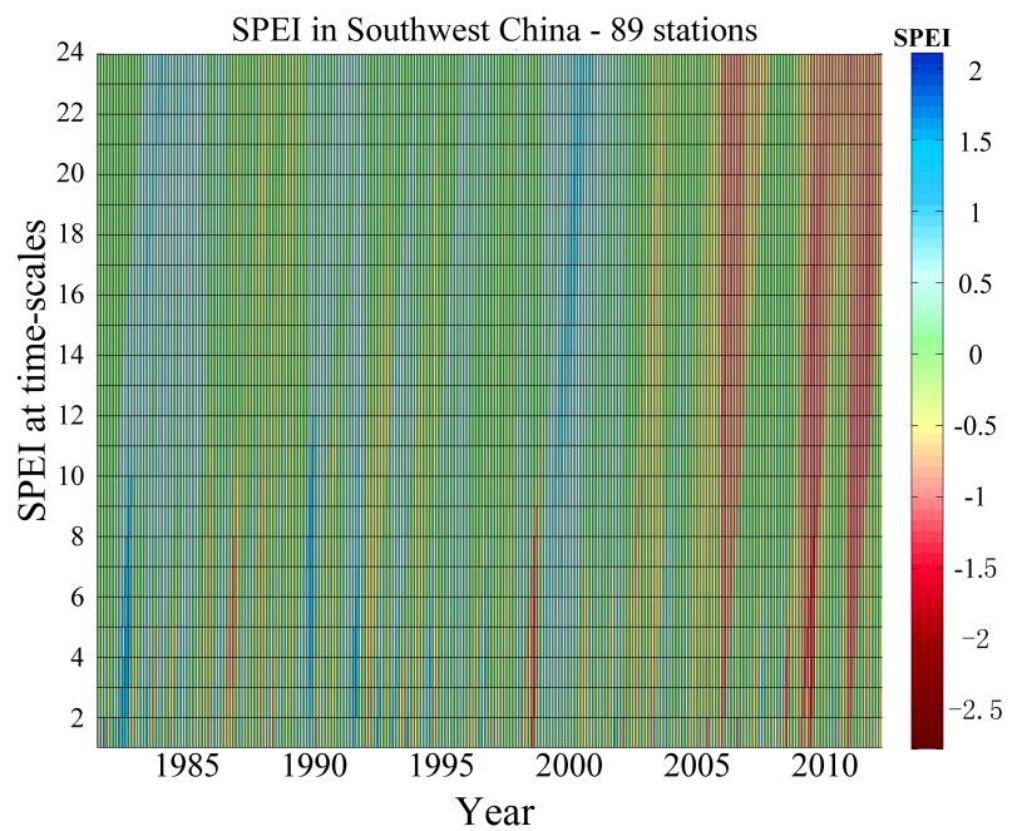

Figure 2. The temporal evolution of the SPEI with 1 to 24-month lags from1982 to 2012 in Southwest China.

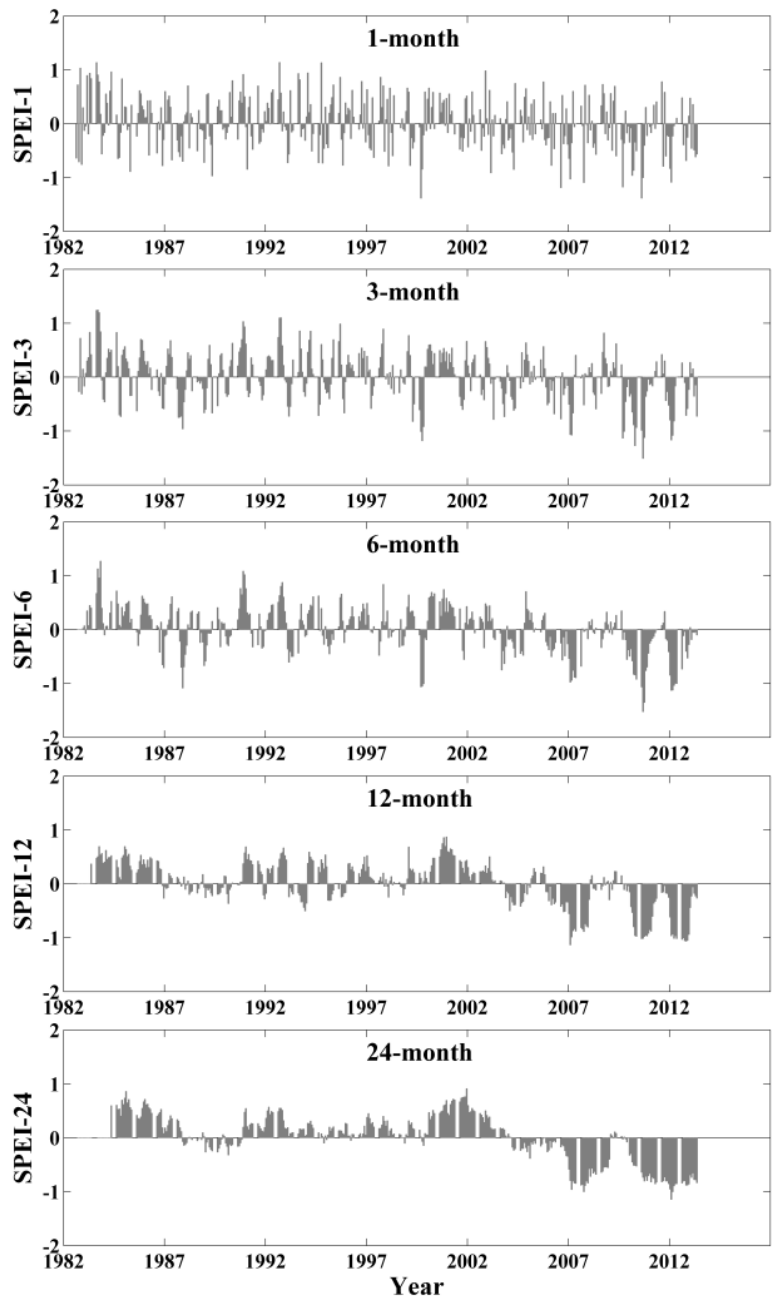

Figure 3. The temporal evolution of SPEI at 1-, 3-, 6-, 12-, and 24-month lags, respectively. 
The Hovmoller-type diagram (Figure 2) explicitly showed an increasing trend of SPEI at 24 time scales during the period 1982-2012 in Southwest China. The SPEI series with different time scales all indicated a drying trend. According to the SPEI values, the moisture conditions were in stark contrast before and after 2005. Before the year of 2005, the study area was mainly characterized by the normal and wet moisture conditions. However, the droughts were frequently occurred after 2005. It could been found some moderate and severe droughts were captured after 2005 and the droughts were even getting aggravated during the period 2010-2012. The temporal evolution of SPEI at 1-, 3-, 6-, 12-, and 24-month lags were displayed in Figure 3. It could be found the most severe drought was recorded in the year of 2010 with several monthly regional-averaged SPEI approximating to -1.5 . This severe drought has already been reported by numerous researches [27,28,35,65-67]. The temporal evolution of SPI at 1-, 3-, 6-, 12-, and 24-month lags were also calculated (not shown), and its difference with SPEI at 1- and 3-month lags were shown in Figure 4. It indicated that the SPEI was gradually lower than SPI and the difference was increasing in recent decade. Especially in 2010, the difference even reached up to -0.5 . The results were likely related to the reported increase of temperature (Section 3.4.1). The increase of temperature enhanced the PET (Equation (1)), which made the water deficit to a high level and thus lowered the value of SPEI.

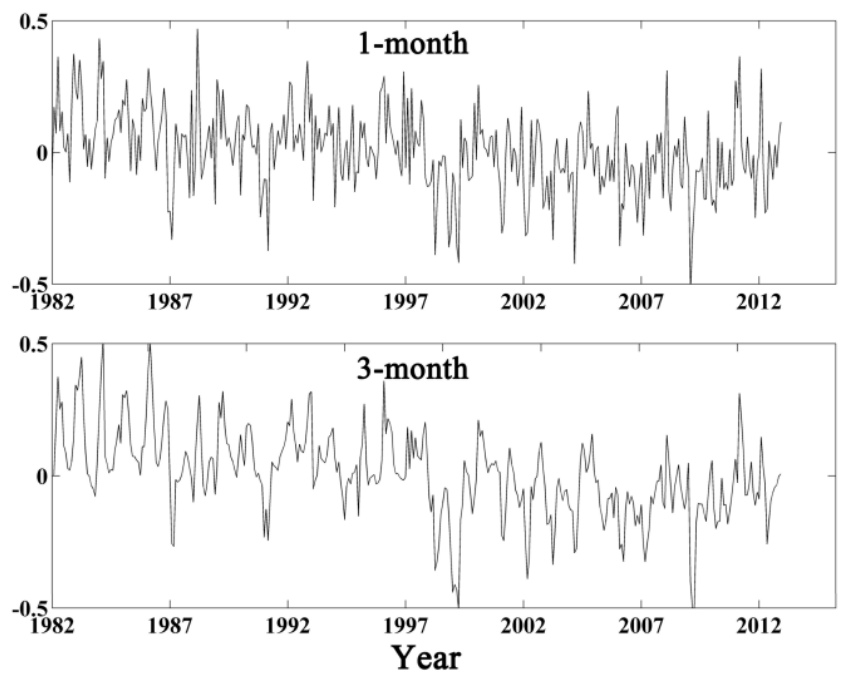

Figure 4. The difference between SPEI and SPI at 1- and 3-month lags. The ordinate denotes the value using SPEI minus SPI.

\subsection{Trend Analysis}

To investigate the overall trend of SPEI in Southwest China, the non-parametric MK test method is applied to analyze the trends of SPEI with different time scales at the 89 stations from 1982 to 2012 . The positive and negative trends, which represent trends towards wetter and drier conditions respectively, were detected. The monthly SPEI series were first averaged for each year at each station for each SPEI accumulation period (1-, 3-, 6-, 12-, and 24-month). In addition, then they were averaged over all 89 stations to obtain the overall trends at the regional level. The same method was also performed with the SPI.

The drying trends of Southwest China were detected from Table 2. The mean SPEI values at five time scales all decreased significantly from 1982 to 2012. The declining trends were statistically significant 
at $99.9 \%$ confidence level for SPEI-24, at 99\% confidence level for SPEI-1, SPEI-6 and SPEI-12, and at $95 \%$ confidence level for SPEI-3. The absolute value of trend was gradually increasing when SPEI was calculated with more lagged months $\left(-0.0111 \mathrm{yr}^{-1}\right.$ for 1 -month, $-0.0136 \mathrm{yr}^{-1}$ for 3 -month, $-0.0168 \mathrm{yr}^{-1}$ for 6-month, $-0.0259 \mathrm{yr}^{-1}$ for 12 -month, and $-0.319 \mathrm{yr}^{-1}$ for 24 -month). It was obvious that the memory of moisture conditions in previous months was accumulated to latter months. Thus, the drying condition of Southwest China was more remarkable when longer months lag was considered. In terms of SPI, the drying trends were also detected. However, the declining trends were not statistically significant at any time scale. The SPEI were decreasing more significantly than the SPI due to the increase of temperature which was consistent with Figure 4.

To obtain the spatial patterns of drought trends, the standardized $\mathrm{Z}$ values of MK test for 89 stations in Southwest China were also provided (Figure 5), which could indicate the increasing or decreasing trend at different confidence levels. Some statistical characteristics were listed in Table 3.

Table 2. The trends of SPI and SPEI at five time scales.

\begin{tabular}{cccccc}
\hline SPEI & Trend & $\mathbf{Z}$ & SPI & Trend & $\mathbf{Z}$ \\
\hline SPEI-1 & -0.0111 & -2.8325 & SPI-1 & -0.0016 & -0.5815 \\
SPEI-3 & -0.0136 & -2.5699 & SPI-3 & -0.0011 & -0.3189 \\
SPEI-6 & -0.0168 & -2.7574 & SPI-6 & -0.0044 & -0.6940 \\
SPEI-12 & -0.0259 & -3.2827 & SPI-12 & -0.0097 & -1.3318 \\
SPEI-24 & -0.0319 & -3.5828 & SPI-24 & -0.0072 & -0.9942 \\
\hline
\end{tabular}

SPEI-1

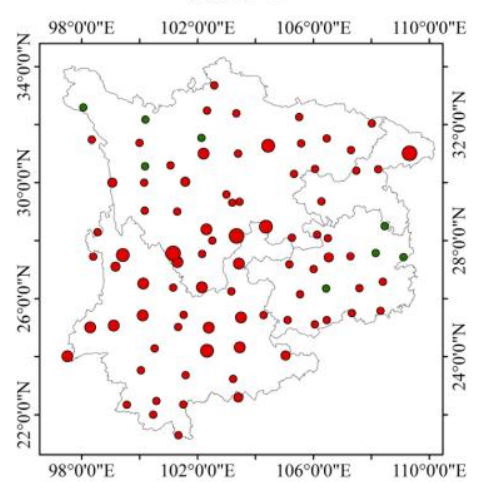

SPEI-12

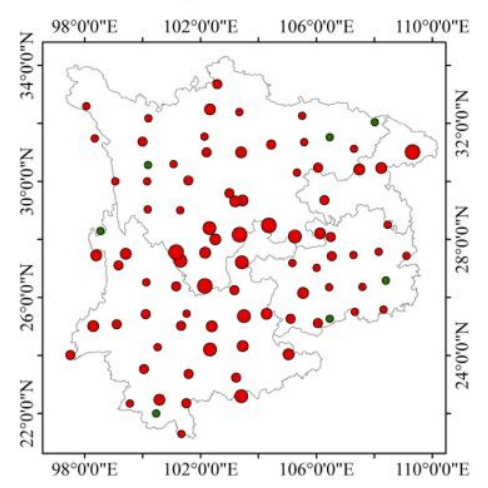

SPEI-3

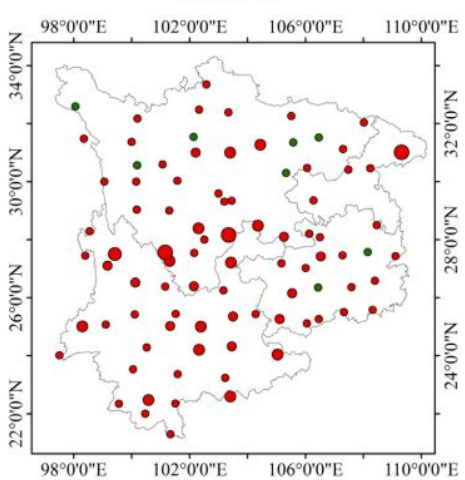

SPEI-24

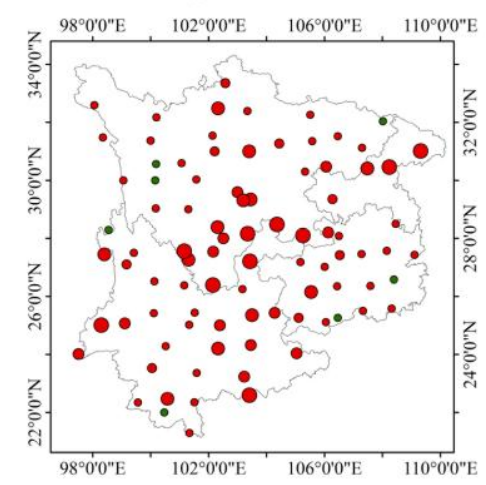

SPEI-6

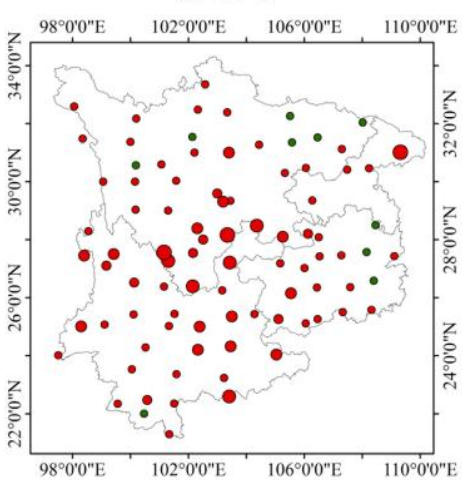

$\mathbf{Z}$

$<=-3.29$

$<=-2.575$

$0<=-1.96$

$0<=-1.645$

$\bullet<=0$

- $>0$ \& $<1.645$

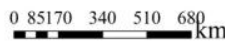

Figure 5. The spatial distribution of the standardized $Z$ values for SPEI at 1-, 3-, 6-, 12-, and 24-month accumulation periods each station in Southwest China. 
Table 3. The statistical characteristics of the standardized $\mathrm{Z}$ values for 89 stations at five accumulation periods. The figures in table represent the corresponding number of stations.

\begin{tabular}{ccccccc}
\hline $\mathbf{Z}$ & Confidence Level & SPEI-1 & SPEI-3 & SPEI-6 & SPEI-12 & SPEI-24 \\
\hline$\leq-3.29$ & $99.9 \%$ & 3 & 3 & 3 & 5 & 10 \\
$(-3.29$ to -2.575$]$ & $99 \%$ & 4 & 1 & 5 & 7 & 12 \\
$(-2.575$ to -1.96$]$ & $95 \%$ & 13 & 12 & 13 & 18 & 12 \\
$(-1.96$ to -1.645$]$ & $90 \%$ & 6 & 11 & 8 & 7 & 8 \\
$(-1.645$ to 0$]$ & - & 55 & 54 & 50 & 45 & 40 \\
$(0$ to 1.645$)$ & - & 8 & 8 & 10 & 7 & 7 \\
\hline
\end{tabular}

The results indicated more than 88.7 percent of stations (82 stations) showed a negative trend of SPEI for all five accumulation periods in Southwest China. The stations with drying trends in the whole region obviously prevailed than that with wetting trends. Like for SPEI-1, the negative trend was statistically significant for more than 26 stations, of which 6 stations at the $90 \%$ confidence level, 13 stations at the $95 \%$ confidence level, 4 stations at the $99 \%$ confidence level, and 3 stations at the $99.9 \%$ confidence level. The distributions of stations with SPEI trends at different confidence levels were generally approximate for five accumulation periods. It could also be found that as the accumulation period of SPEI increased (from 1 to 24 months), the number of stations with significantly negative trend was increasing (seen in SPEI-12/24 at 99\% and 99.9\% confidence levels). The memory of moisture conditions in previous months was accumulated to latter months in some stations. As for SPEI trends of other four periods, the detailed distributions of stations at different confidence levels were not stated here.

\subsection{The Temporal and Spatial Extent of Drought}

To further assess the interannual variability of the drought, two experiments were performed to obtain the duration and severity. In addition, they were considered to represent the temporal and spatial extent of the drought.

\subsubsection{Temporal Extent}

In this study, the duration of the drought events (defined as SPEI $\leq-1$ ) at each station for each year was calculated. The duration is expressed in number of months. Then, the durations for all 89 stations each year were averaged to overall temporal extent of the drought at regional scale.

Figure 6 provided the mean number of dry months each year from 1982 to 2012. The different accumulation periods of SPEI were also considered. The aggravating condition of the drought was explicitly realized. Generally, there were merely about two dry months before 2000 . However, the dry months in recent years were significantly increasing. The mean number of dry months reached to four, and the maximum number was even greater than six months (SPEI-24 in 2011 and 2012). The different accumulation periods of SPEI can represent drought conditions on different aspects. The SPEI with one month conveys meteorological drought identification. At the 3-6-month time scales it represents the drought in agricultural aspect, and at 6-12-month time scales it can be a hydrological drought index, useful for monitoring surface water resources $[8,17]$. Before the year of 2000 , the mean numbers of dry months for different accumulation periods of SPEI were generally comparative. The meteorological and 
agricultural drought were slightly severe than the hydrological drought. However, a quick transition occurred. The moisture deficiency in hydrological aspect overwhelmed than which in meteorological and agricultural aspects. Especially in 2010-2012, the mean numbers of dry months for SPEI-12/24 were 5.1 and 6.1, respectively, which exceeded the numbers of SPEI with less accumulation periods (2.8 months for SPEI-1, 3.2 months for SPEI-3 and 3.8 months for SPEI-6). The previous moisture deficiency was accumulated when calculating the SPEI with longer accumulation periods. The moisture deficiency led to the meteorological and agricultural drought, and further caused the aggravating of hydrological drought.

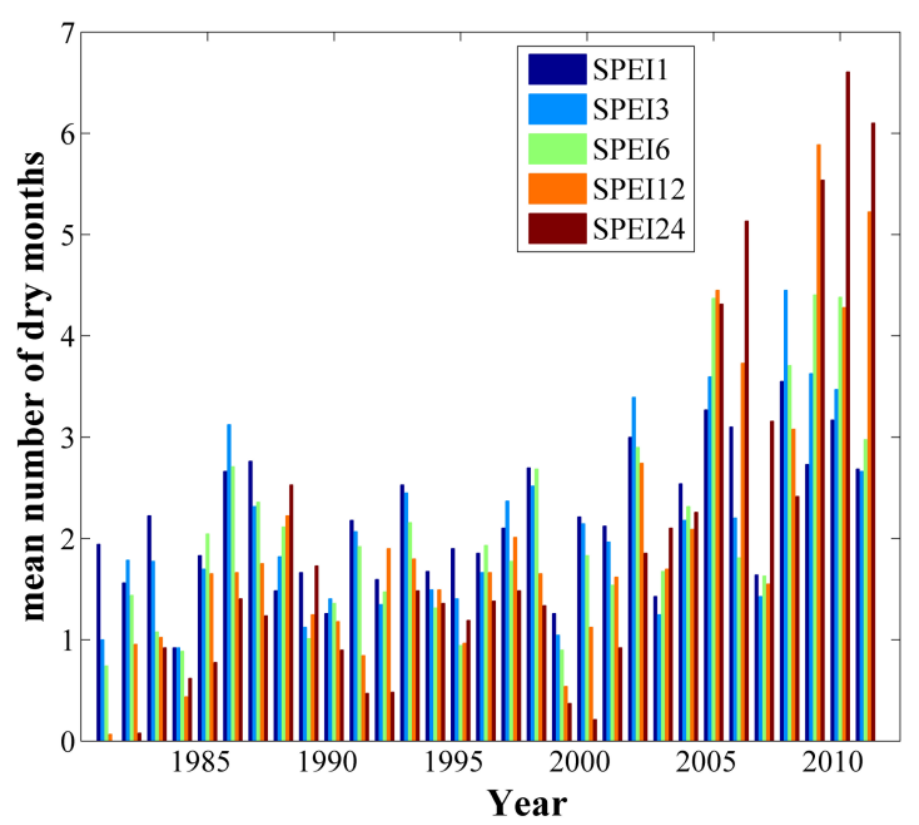

Figure 6. The mean number of dry months (SPEI $\leq-1)$ each year from 1982 to 2012.

\subsubsection{Spatial Extent}

Next, another indicator was considered to evaluate the severity of the drought [8].The relatively high density of climatological stations in Southwest China facilitates us to assess the spatial extent of the drought approximately. In this case, we counted the percent of stations with different dry months (SPEI $\leq-1)$ each year. For simplicity, the percent of stations with more than three and six dry months each year were illustrated in Figure 7. Other cases were not listed here.

The results were consistent with above findings. From Figure $7 \mathrm{a}$, the percent of stations with more than three dry months each year was increasing from 1982 to 2012. The most extensive droughts were recorded after the year of 2005, and especially in 2010, about $58 \%$ of stations were suffering the meteorological drought more than three months, and about $67 \%$ of stations were suffering the agricultural drought, and about $70 \%$ of stations were suffering the hydrological drought.

Similarly, Figure $7 \mathrm{~b}$ illustrated the percent of stations with more than six dry months each year from 1982 to 2012. The increasing trend was more significant in this case. The percent of stations with meteorological drought more than six months was generally less than $5 \%$ before 2005 , and with agricultural and hydrological drought more than six months was less than $20 \%$. However, they all increased to a great degree in recent several years. 

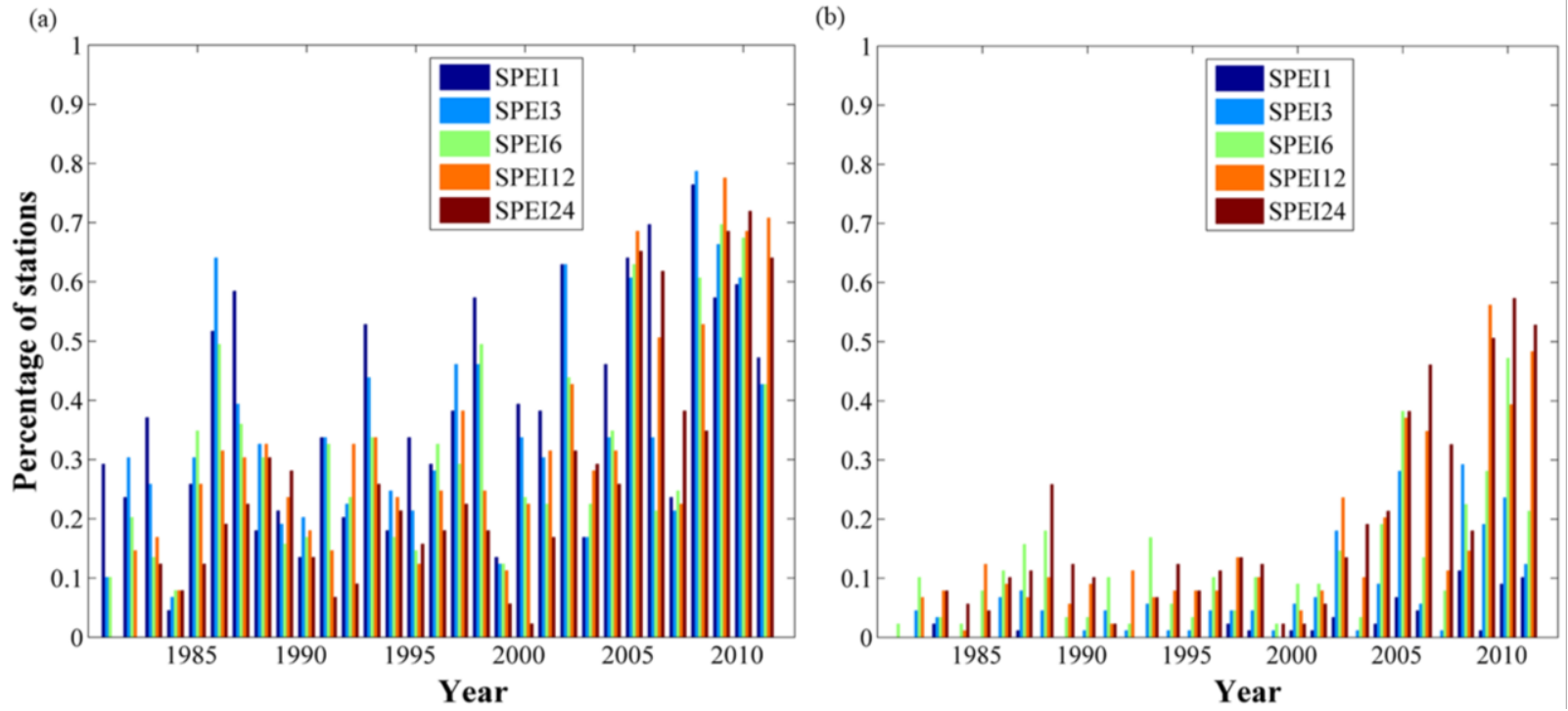

Figure 7. Percentage of stations with (a) more than three dry months and (b) more than six dry months each year.

\subsection{The Performance of SPEI}

\subsubsection{The Performance of SPEI in Monitoring the Soil Moisture}

The correlation analysis was conducted at a monthly basis between the SMCI and SPI/SPEI at five accumulation periods. The results which provided the averaged correlations of stations in Southwest China were given in Table 4.

Table 4. The averaged correlations of the stations obtained each month between the SMCI and SPI/SPEI at five accumulation periods in Southwest China.

\begin{tabular}{ccccccccccc}
\hline Month & SPI-1 & SPEI-1 & SPI-3 & SPEI-3 & SPI-6 & SPEI-6 & SPI-12 & SPEI-12 & SPI-24 & SPEI-24 \\
\hline Jan. & 0.3943 & 0.4031 & 0.5388 & 0.4892 & 0.2716 & 0.2553 & 0.2158 & 0.2038 & 0.1538 & 0.1391 \\
Feb. & 0.5167 & 0.5316 & 0.5621 & 0.5897 & 0.3847 & 0.4020 & 0.1635 & 0.1753 & 0.1504 & 0.1553 \\
Mar. & 0.4862 & 0.5349 & 0.6326 & 0.6685 & 0.3962 & 0.4745 & 0.1389 & 0.1941 & 0.0708 & 0.1010 \\
Apr. & 0.3777 & 0.4227 & 0.5126 & 0.5235 & 0.3744 & 0.4024 & 0.1166 & 0.1377 & 0.0506 & 0.0539 \\
May. & 0.5105 & 0.5307 & 0.5149 & 0.5112 & 0.4955 & 0.4755 & 0.1519 & 0.1233 & 0.1457 & 0.1083 \\
Jun. & 0.3237 & 0.3390 & 0.4607 & 0.4598 & 0.4594 & 0.4469 & 0.2914 & 0.2815 & 0.2099 & 0.1856 \\
Jul. & 0.4264 & 0.4390 & 0.4297 & 0.4290 & 0.3980 & 0.3802 & 0.2482 & 0.2201 & 0.1787 & 0.1759 \\
Aug. & 0.5760 & 0.5767 & 0.5115 & 0.5157 & 0.4613 & 0.4486 & 0.3987 & 0.3822 & 0.2651 & 0.2358 \\
Sep. & 0.4467 & 0.4617 & 0.4779 & 0.4758 & 0.3939 & 0.3909 & 0.3366 & 0.3355 & 0.2204 & 0.2153 \\
Oct. & 0.4811 & 0.4749 & 0.4272 & 0.4183 & 0.3036 & 0.3008 & 0.2536 & 0.2509 & 0.1694 & 0.1605 \\
Nov. & 0.5597 & 0.5301 & 0.4943 & 0.4629 & 0.3095 & 0.3008 & 0.2777 & 0.2666 & 0.1821 & 0.1740 \\
Dec. & 0.3457 & 0.3649 & 0.4957 & 0.4670 & 0.3102 & 0.2924 & 0.2400 & 0.2155 & 0.1226 & 0.1015 \\
\hline
\end{tabular}

The SPI and SPEI had approximate correlations with the SMCI. For both SPI and SPEI, the correlations were generally higher at short to moderate timescale (1-, 3-, and 6-month). The highest correlation was obtained between SMCI and the 3-month SPI/SPEI with annual mean value of correlation more than 0.5 . 
Figure 8 shows the box plots displaying the detailed correlations between the SMCI and SPI/SPEI obtained each month for all the stations at five accumulation periods in Southwest China. By examining the correlations with 3-month SPI/SPEI, the SPEI tended to perform better than the SPI. The correlation between the SMCI and SPEI was higher than that of SPI in February, March, April, and October and lower in January, November, and December and comparable in other months. In February, March, and April, the correlations for five accumulation periods of SPEI were all higher than that of SPI. In addition, especially in February and March, the SPEI significantly outperformed the SPI. The SPEI uses temperature and precipitation as input while the SPI only uses precipitation. Therefore the least square method was applied to detect the temperature trend each month from 1982 to 2012.
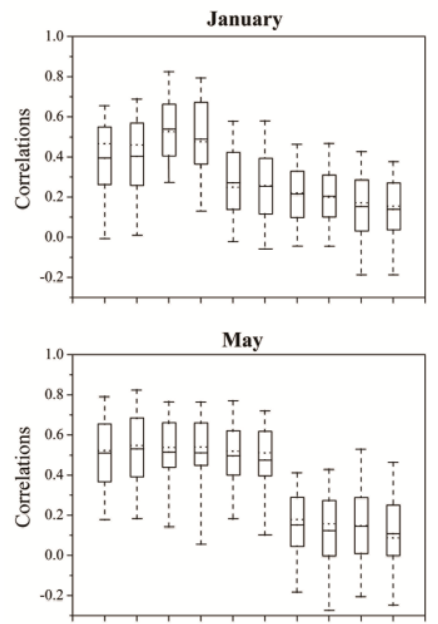

September

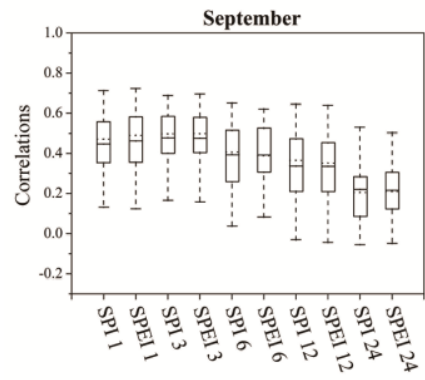

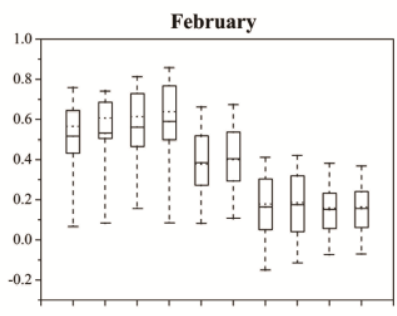

June

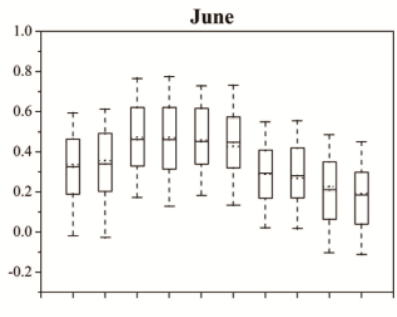

October

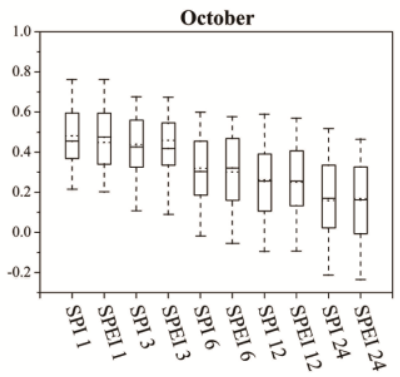

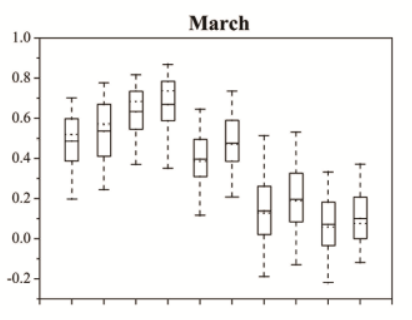

July

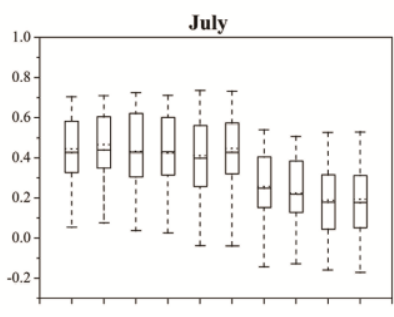

November

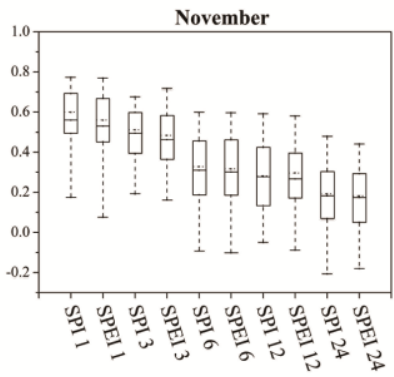

April

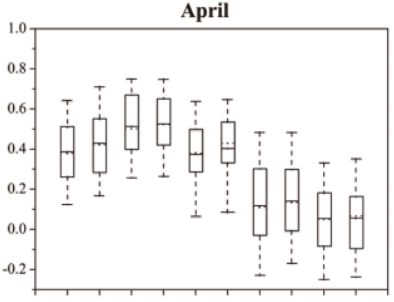

August

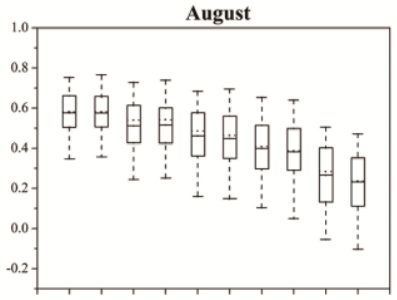

December

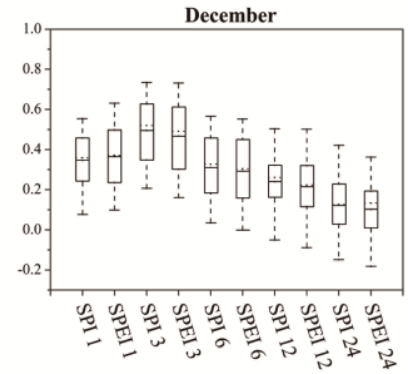

Figure 8. The box plots displaying the detailed correlations between SMCI and SPI/SPEI obtained each month for all the stations at five accumulation periods in Southwest China. Solid lines extend from 5 th to 95 th percentile of estimations, boxes extend from 25 th to 75 th percentile, and middle horizontal solid and dashed line within each box indicate the mean and the median value, respectively.

The trend and its statistical significance in each month were given in Table 5. In past three decades, the temperature of Southwest China was increasing in all months, and with three largest trends occurring in February, March, and April (Figure 9). The results were highly consistent with the correlations between SMCI and SPI/SPEI. The significant increase of temperature in those three months aggravated the drying condition of the study area and therefore the SPEI which incorporated the temperature into the calculation of potential evapotranspiration could represent the dry and wet conditions to a higher degree. 
Table 5. The trend of the temperature from 1982 to 2012in each month and p denotes the statistical significance.

\begin{tabular}{ccccccc}
\hline Month & Jan. & Feb. & Mar. & Apr. & May. & Jun. \\
\hline trend & 0.0382 & 0.0799 & 0.0708 & 0.0542 & 0.0067 & 0.0070 \\
p & 0.0417 & 0.0074 & 0.0003 & 0.0047 & 0.6548 & 0.5639 \\
Month & Jul. & Aug. & Sep. & Oct. & Nov. & Dec. \\
trend & 0.0351 & 0.0258 & 0.0519 & 0.0292 & 0.0179 & 0.0419 \\
p & 0.0017 & 0.0601 & 0.0006 & 0.0696 & 0.1995 & 0.0020 \\
\hline
\end{tabular}

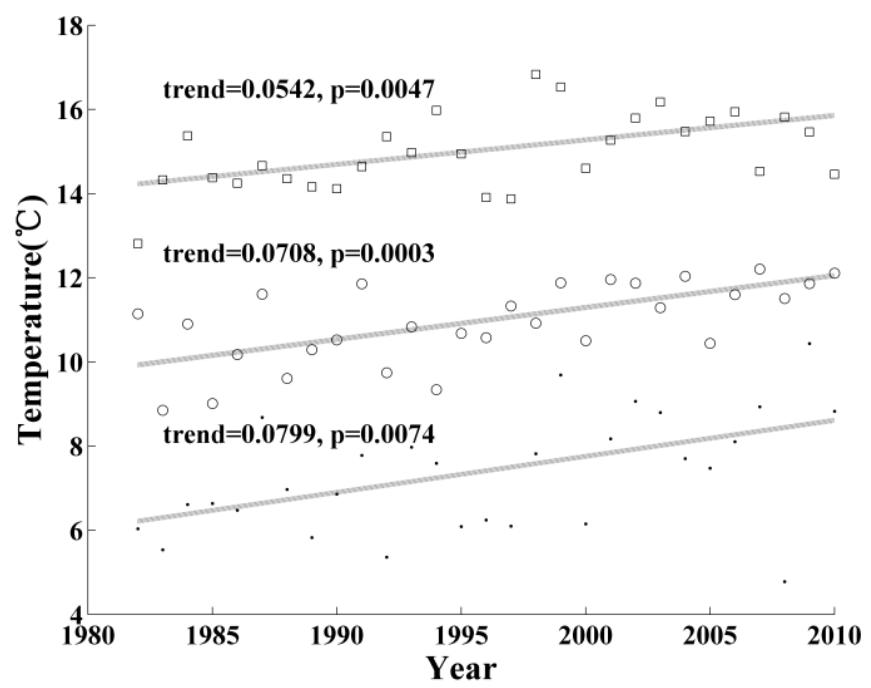

Figure 9. The trend of the temperature from 1982 to 2012 and its statistical significance in February, March, and April. The dot denotes the temperature in February, the circle denotes the temperature in March and the square denotes the temperature in April.

\subsubsection{The Performance of SPEI in Monitoring the Vegetation Drought}

The correlation analysis was conducted at a monthly basis during the growing season (from April to October) between the VCI and SPI/SPEI for five accumulation periods. The results which provided the averaged and maximum correlations of stations in Southwest China were given in Table 6 and Table 7, respectively.

For both SPI and SPEI, the correlations were higher when calculated with longer accumulation periods, suggesting that the lag time between precipitation occurrence and vegetation response was longer in our study area. The highest correlations for different months were obtained between VCI and the 3-12 month SPI/SPEI. In addition, the averaged correlations for each accumulation period were generally low, indicating that the vegetation growth was insusceptible to meteorological moisture deficit. In Southwest China, the annual precipitation is generally above $900 \mathrm{~mm}$, and thus in such moist condition the sensitivity of vegetation growth to precipitation is naturally low. The results were generally consistent with [9,51]. In [9], the highest correlation between VCI and SPI was obtained in a region with lowest precipitation, and vice versa. Similarly in [51], the correlation between scaled NDVI and in situ indices in arid regions was $0.33-0.51$, but in humid regions the maximum correlation was no more than 0.25. 
Nevertheless, by examining either the averaged correlations or maximum correlations between the VCI and SPI/SPEI, it could be found that the SPEI was slightly superior to the SPI which was similar to the results in monitoring the soil moisture but with a smaller difference. Therefore, the performance of SPEI in Southwest China has been well demonstrated.

Table 6. The averaged correlations of the stations obtained during the growing season between the VCI and SPI/SPEI for five accumulation periods in Southwest China.

\begin{tabular}{ccccccccccc}
\hline Month & SPI-1 & SPEI-1 & SPI-3 & SPEI-3 & SPI-6 & SPEI-6 & SPI-12 & SPEI-12 & SPI-24 & SPEI-24 \\
\hline Apr. & 0.1361 & 0.1337 & 0.1682 & 0.1404 & 0.2252 & 0.1797 & 0.1594 & 0.1638 & 0.1486 & 0.1322 \\
May. & 0.1820 & 0.1760 & 0.2001 & 0.1905 & 0.1947 & 0.1838 & 0.1991 & 0.2059 & 0.1851 & 0.1850 \\
Jun. & 0.0837 & 0.0739 & 0.1412 & 0.1393 & 0.1469 & 0.1448 & 0.2436 & 0.2170 & 0.1954 & 0.1913 \\
Jul. & 0.1295 & 0.1353 & 0.1379 & 0.1545 & 0.1448 & 0.1599 & 0.1726 & 0.1885 & 0.1873 & 0.1900 \\
Aug. & 0.1488 & 0.1469 & 0.1490 & 0.1484 & 0.1707 & 0.1606 & 0.1626 & 0.1551 & 0.1726 & 0.1853 \\
Sep. & 0.1145 & 0.1439 & 0.2239 & 0.2168 & 0.2209 & 0.2121 & 0.2132 & 0.1968 & 0.1943 & 0.1984 \\
Oct. & 0.1076 & 0.1243 & 0.1445 & 0.1425 & 0.1300 & 0.1242 & 0.1174 & 0.1159 & 0.1288 & 0.1292 \\
\hline
\end{tabular}

Table 7. The maximum correlations of the stations obtained during the growing season between the VCI and SPI/SPEI for five accumulation periods in Southwest China.

\begin{tabular}{ccccccccccc}
\hline Month & SPI-1 & SPEI-1 & SPI-3 & SPEI-3 & SPI-6 & SPEI-6 & SPI-12 & SPEI-12 & SPI-24 & SPEI-24 \\
\hline Apr. & 0.4052 & 0.4711 & 0.4930 & 0.5665 & 0.4273 & 0.5147 & 0.3825 & 0.3871 & 0.4135 & 0.3857 \\
May. & 0.3982 & 0.5092 & 0.4897 & 0.5617 & 0.4941 & 0.5481 & 0.5066 & 0.5448 & 0.5922 & 0.5889 \\
Jun. & 0.2212 & 0.2046 & 0.3292 & 0.2790 & 0.3994 & 0.3225 & 0.5768 & 0.6545 & 0.4616 & 0.4791 \\
Jul. & 0.4014 & 0.3913 & 0.5213 & 0.5046 & 0.4930 & 0.4835 & 0.7210 & 0.6982 & 0.5242 & 0.5092 \\
Aug. & 0.3644 & 0.4236 & 0.5104 & 0.5072 & 0.4785 & 0.4378 & 0.4202 & 0.4047 & 0.4224 & 0.4640 \\
Sep. & 0.2713 & 0.2797 & 0.5667 & 0.5635 & 0.5407 & 0.5417 & 0.5261 & 0.5257 & 0.5185 & 0.5092 \\
Oct. & 0.2950 & 0.3113 & 0.4492 & 0.4596 & 0.4417 & 0.4489 & 0.4539 & 0.4347 & 0.3670 & 0.3446 \\
\hline
\end{tabular}

\section{Conclusions}

As in Southwest China, the fact that the increase of temperature contributes to some severe droughts in recent years is recognized. In this study, a drought index SPEI, calculated by both precipitation and temperature was used to provide a comprehensive analysis of the drought characteristics in Southwest China from 1982-2012. The multi-scale patterns, the trend, and the spatio-temporal extent of the drought were evaluated, respectively. In addition, the correlation analysis between SPEI and two remotely sensed indices was conducted to investigate the performance of SPEI. The main conclusions are summarized as follows:

(1) A drying trend of Southwest China was explicitly detected by SPEI series with different time scales. Some moderate and severe droughts were captured after 2005 and the droughts were even getting aggravated during the period 2010-2012.

(2) The results of MK test indicated that the mean SPEI values at five time scales (1-, 3-, 6-, 12-, and 24-month) all decreased significantly from 1982 to 2012. The absolute value of declining trend was gradually increasing when SPEI was calculated with more lagged months. 
(3) The aggravating condition of the drought was realized by examining the spatio-temporal extent. The numbers of dry months were significantly increasing and the percent of stations with more than three and six dry months each year were also increasing to a great extent.

(4) The correlations analysis between the SMCI and SPI/SPEI demonstrated that the highest correlation was obtained between SMCI and the 3-month SPI/SPEI. In this case, the SPEI tended to perform better than the SPI. The correlation between the SMCI and SPEI was significantly higher than that of SPI in February, March, and April, with all months characterized by significant increase of temperature.

(5) The correlations analysis between the VCI and SPI/SPEI indicated that for both SPI and SPEI, the correlations between the VCI and SPI/SPEI were generally low, suggesting that in moist areas vegetation growth was less sensitive to precipitation. Nevertheless, the SPEI was slightly superior to the SPI which was similar to the results in monitoring the soil moisture but with a smaller difference.

The performance of SPEI in monitoring the drought in Southwest China has been well demonstrated. However, the correlations between the VCI and SPI/SPEI were generally low, suggesting in moist areas like Southwest China the sensitivity of vegetation growth to long-term precipitation is low, which makes that the SPEI outperform the SPI only to a little extent. It is appropriate to assume that in some semi-arid and arid regions, the sensitivity of vegetation growth to precipitation is naturally increasing, and thus with increase of temperature, the superiority of the SPEI is expected to be improved. Future work will be dedicated to making such an attempt in semi-arid and arid regions.

In this study, we use SPEI to monitor the drought because it is an improved index of SPI by considering both precipitation and temperature and its multi-temporal characteristic facilitates us to analyze at different temporal scales to evaluate the different types of drought. Other widely used in situ drought indices such as PDSI and its improved variants are not considered at present. In our further researches, comprehensive analyses on the performance between different in situ drought indices will be conducted.

\section{Acknowledgments}

This work was supported by National Natural Science Foundation of China (Contract No. 41471293), the Fundamental Research Fund for the Central Universities (Contract No. ZYGX2012Z005), and the National High-Tech Research and Development Program of China (Contract 2013AA12A302). The authors wish to thank Changming Yin, Youyou Li, Yuwei Guan and Zhi Tang for their assistance during the experiment.

\section{Author Contributions}

The idea was conceived by Xing Li and Binbin He, performed by Xing Li, analyzed by Xing Li, Xingwen Quan, and Zhanmang Liao, written by Xing Li and Binbin He, and revised by Xiaojing Bai and Xingwen Quan.

\section{Conflicts of Interest}

The authors declare no conflict of interest. 


\section{References}

1. Törnros, T.; Menzel, L. Addressing drought conditions under current and future climates in the Jordan River region. Hydrol. Earth Syst. Sci. 2014, 18, 305-318.

2. Sahoo, A.K.; Sheffield, J.; Pan, M.; Wood, E.F. Evaluation of the tropical rainfall measuring mission multi-satellite precipitation analysis (TMPA) for assessment of large-scale meteorological drought. Remote Sens. Environ. 2015, 159, 181-193.

3. Du, L.; Tian, Q.; Yu, T.; Meng, Q.; Jancso, T.; Udvardy, P.; Huang, Y. A comprehensive drought monitoring method integrating MODIS and TRMM data. Int. J. Appl. Earth Obs. 2013, 23, 245-253.

4. Chen, T.; Werf, G.; Jeu, R.; Wang, G.; Dolman, A. A global analysis of the impact of drought on net primary productivity. Hydrol. Earth Syst. Sci. 2013, 17, 3885-3894.

5. Council, A. AMS statement on meteorological drought. Bull. Am. Meteor. Soc. 2004, 85, 771-773.

6. Benitez, J.B.; Domecq, R.M. Analysis of meteorological drought episodes in Paraguay. Climatic Change 2014, 127, 15-25.

7. Mishra, A.K.; Singh, V.P. Drought modeling-A review. J. Hydrol. 2011, 403, 157-175.

8. Potop, V.; Boroneanţ, C.; Možný, M.; Štěpánek, P.; Skalák, P. Observed spatiotemporal characteristics of drought on various time scales over the Czech Republic. Theor. Appl. Climatol. 2014, 115, 563-581.

9. Zhang, A.; Jia, G. Monitoring meteorological drought in semiarid regions using multi-sensor microwave remote sensing data. Remote Sens. Environ. 2013, 134, 12-23.

10. Vicente-Serrano, S.M.; Beguería, S.; Lorenzo-Lacruz, J.; Camarero, J.J.; López-Moreno, J.I.; Azorin-Molina, C.; Revuelto, J.; Morán-Tejeda, E.; Sanchez-Lorenzo, A. Performance of drought indices for ecological, agricultural, and hydrological applications. Earth Interact. 2012, 16, 1-27.

11. Heim, R.R. Drought indices: A review. In Drought: A Global Assessment; Routledge: London, UK, 2000; Volume 1, pp. 159-167.

12. Rajsekhar, D.; Singh, V.P.; Mishra, A.K. Multivariate drought index: An information theory based approach for integrated drought assessment. J. Hydrol. 2015, 526, 164-182.

13. Wang, Q.; Shi, P.; Lei, T.; Geng, G.; Liu, J.; Mo, X.; Li, X.; Zhou, H.; Wu, J. The alleviating trend of drought in the Huang-Huai-Hai plain of China based on the daily SPEI. Int. J. Climatol. 2015, doi:10.1002/joc.4244.

14. Yan, H.; Wang, S.Q.; Lu, H.Q.; Yu, Q.; Zhu, Z.C.; Myneni, R.B.; Liu, Q.; Shugart, H.H. Development of a remotely sensing seasonal vegetation-based Palmer drought severity index and its application of global drought monitoring over 1982-2011. J. Geophys. Res. 2014, 119, 9419-9440.

15. Guttman, N.B. Comparing the Palmer drought index and the standardized precipitation index. J. Am. Water. Resour. Assoc. 1998, 34, 113-121.

16. Palmer, W.C. Meteorological Drought. Research Paper No.45. Available online: https://www.ncdc.noaa.gov/temp-and-precip/drought/docs/palmer.pdf (accessed on 14 July 2015).

17. McKee, T.B.; Doesken, N.J.; Kleist, J. The relationship of drought frequency and duration to time scales. In Proceedings of the 8th Conference on Applied Climatology, Boston, MA, USA, 17-22 January 1993. 
18. Vicente-Serrano, S.M.; Beguería, S.; López-Moreno, J.I. A multiscalar drought index sensitive to global warming: The standardized precipitation evapotranspiration index. J. Climate 2010, 23, 1696-1718.

19. Potopová, V.; Štěpánek, P.; Možný, M.; Türkott, L.; Soukup, J. Performance of the standardized precipitation evapotranspiration index at various lags for agricultural drought risk assessment in the Czech Republic. Agr. Forest Meteorol. 2015, 202, 26-38.

20. Yu, M.; Li, Q.; Hayes, M.J.; Svoboda, M.D.; Heim, R.R. Are droughts becoming more frequent or severe in China based on the standardized precipitation evapotranspiration index: 1951-2010? Int. J. Climatol. 2014, 34, 545-558.

21. Xu, X.; Piao, S.; Wang, X.; Chen, A.; Ciais, P.; Myneni, R.B. Spatio-temporal patterns of the area experiencing negative vegetation growth anomalies in China over the last three decades. Environ. Res. Lett. 2012, doi:10.1088/1748-9326/7/3/035701.

22. Wu, Z.Y.; Lu, G.H.; Wen, L.; Lin, C. Reconstructing and analyzing China's fifty-nine year (1951-2009) drought history using hydrological model simulation. Hydrol. Earth. Syst. Sci. 2011, 15, 2881-2894.

23. Zhai, J.; Su, B.; Krysanova, V.; Vetter, T.; Gao, C.; Jiang, T. Spatial variation and trends in PDSI and SPI indices and their relation to streamflow in 10 large regions of China. J. Climate 2010, 23, 649-663.

24. Ma, Z.G.; Ren, X.B. Drying trend over China from 1951 to 2006. Adv. Climate Change Res. 2007, 3, 195-201.

25. Liu, M.; Xu, X.; Sun, A.Y.; Wang, K.; Liu, W.; Zhang, X. Is southwestern China experiencing more frequent precipitation extremes? Environ. Res. Lett. 2014, doi:10.1088/1748-9326/9/6/064002.

26. Peng, J.; Zhang, Q.; Bueh, C. On the characteristics and possible causes of a severe drought and heat wave in the Sichuan-Chongqing region in 2006. Climatic Environ. Res. 2007, 12, 464-474.

27. Zhang, L.; Xiao, J.; Li, J.; Wang, K.; Lei, L.; Guo, H. The 2010 spring drought reduced primary productivity in southwestern China. Environ. Res. Lett. 2012, 7, 045706.

28. Yang, J.; Gong, D.; Wang, W.; Hu, M.; Mao, R. Extreme drought event of 2009/2010 over southwestern China. Meteorol. Atmos. Phys. 2012, 115, 173-184.

29. Lu, E.; Luo, Y.; Zhang, R.; Wu, Q.; Liu, L. Regional atmospheric anomalies responsible for the 2009-2010 severe drought in China. J. Geophys. Res. 2011, doi:10.1029/2011JD015706.

30. Wang, X.; Xie, H.; Guan, H.; Zhou, X. Different responses of MODIS-derived NDVI to root-zone soil moisture in semi-arid and humid regions. J. Hydrol. 2007, 340, 12-24.

31. Gu, Y.; Hunt, E.; Wardlow, B.; Basara, J.B.; Brown, J.F.; Verdin, J.P. Evaluation of MODIS NDVI and NDWI for vegetation drought monitoring using Oklahoma Mesonet soil moisture data. Geophys. Res. Lett. 2008, 35, doi:10.1029/2008GL035772.

32. Long, D.; Yang, Y.T; Wada, Y.; Hong, Y.; Liang, W.; Chen, Y.N.; Yong. B.; Hou. A.Z.; Wei. J.F.; Chen, L. Deriving scaling factors using a global hydrological model to restore GRACE total water storage changes for China's Yangtze River Basin. Remote Sens. Environ. 2015, 168, 177-193.

33. Qin, N.; Chen, X.; Fu, G.; Zhai, J.; Xue, X. Precipitation and temperature trends for the Southwest China: 1960-2007. Hydrol. Process 2010, 24, 3733-3744.

34. Liu, M.; Xu, X.; Sun, A. Decreasing spatial variability in precipitation extremes in southwestern China and the local/large-scale influencing factors. J. Geophys. Res. 2015, 120, 6480-6488. 
35. Wang, W.; Wang, W.J.; Li, J.S.; Wu, H.; Xu, C.; Liu, T. The impact of sustained drought on vegetation ecosystem in Southwest China based on remote sensing. Procedia Environ. Sci. 2010, 2, 1679-1691.

36. Hao, C.; Zhang, J.; Yao, F. Combination of multi-sensor remote sensing data for drought monitoring over Southwest China. Int. J. Appl. Earth Obs. 2015, 35, 270-283.

37. Beguería, S.; Vicente-Serrano, S.M.; Reig, F.; Latorre, B. Standardized precipitation evapotranspiration index (SPEI) revisited: Parameter fitting, evapotranspiration models, tools, datasets and drought monitoring. Int. J. Climatol. 2014, 34, 3001-3023.

38. Thornthwaite, C.W. An approach toward a rational classification of climate. Geogr. Rev. 1948, 55-94.

39. Abramowitz, M.; Stegun, I.A. Handbook of Mathematical Functions; Dover: NewYork, NY, USA, 1965.

40. Dataset of Daily Precipitation and Temperature from China Meteorological Data Sharing Service System. Available online: http://cdc.cma.gov.cn (accessed on 5 April 2015).

41. Jiang, L.; Islam, S. Estimation of surface evaporation map over southern great plains using remote sensing data. Water Resour. Res. 2001, 37, 329-340.

42. He, B.; Li, X.; Quan, X.W; Qiu, S. Estimating the aboveground dry biomass of grass by assimilation of retrieved lai into a crop growth model. IEEE J. Sel. Top. App. Remote Sens. 2015, 8, 550-561.

43. Quan, X.W.; He, B.; Wang, Y.; Tang, Z.; Li, X. An extended Fourier approach to improve the retrieved leaf area index (LAI) in a time series from an alpine wetland. Remote Sens. 2014, 6, 1171-1190.

44. Kogan, F.N. Droughts of the late 1980s in the United States as derived from NOAA polar-orbiting satellite data. B. Am. Meteorol. Soc. 1995, 76, 655-668.

45. Kogan, F. Application of vegetation index and brightness temperature for drought detection. Adv. Space Res. 1995, 15, 91-100.

46. Yang, Y.; Long, D.; Guan, H.; Scanlon, B.R.; Simmons, C.T.; Jiang, L.; Xu, X. GRACE satellite observed hydrological controls on interannual and seasonal variability in surface greenness over mainland Australia. J. Geophys. Res. 2014, 119, 2245-2260.

47. Xu, G.; Zhang, H.; Chen, B.; Zhang, H.; Innes, J.L.; Wang, G.; Yan, J.; Zheng, Y.; Zhu, Z.; Myneni, R.B. Changes in vegetation growth dynamics and relations with climate over China's landmass from 1982 to 2011. Remote Sens. 2014, 6, 3263-3283.

48. Chen, B.; Xu, G.; Coops, N.C.; Ciais, P.; Innes, J.L.; Wang, G.; Myneni, R.B.; Wang, T.; Krzyzanowski, J.; Li, Q. Changes in vegetation photosynthetic activity trends across the Asia-Pacific region over the last three decades. Remote Sens. Environ. 2014, 144, 28-41.

49. Peters, A.J.; Walter-Shea, E.A.; Ji, L.; Vina, A.; Hayes, M.; Svoboda, M.D. Drought monitoring with NDVI-based standardized vegetation index. Photogramm. Eng. Remote Sens. 2002, 68, 71-75.

50. Quiring, S.M.; Ganesh, S. Evaluating the utility of the vegetation condition index (VCI) for monitoring meteorological drought in Texas. Agr. Forest Meteorol. 2010, 150, 330-339.

51. Rhee, J.; Im, J.; Carbone, G.J. Monitoring agricultural drought for arid and humid regions using multi-sensor remote sensing data. Remote Sens. Environ. 2010, 114, 2875-2887.

52. Bayarjargal, Y.; Karnieli, A.; Bayasgalan, M.; Khudulmur, S.; Gandush, C.; Tucker, C. A comparative study of NOAA-AVHRR derived drought indices using change vector analysis. Remote Sens. Environ. 2006, 105, 9-22. 
53. Tucker, C.J.; Pinzon, J.E.; Brown, M.E.; Slayback, D.A.; Pak, E.W.; Mahoney, R.; Vermote, E.F.; El Saleous, N. An extended AVHRR 8-km NDVI dataset compatible with MODIS and SPOT vegetation NDVI data. Int. J. Remote Sens. 2005, 26, 4485-4498.

54. Barichivich, J.; Briffa, K.R.; Myneni, R.B.; Osborn, T.J.; Melvin, T.M.; Ciais, P.; Piao, S.; Tucker, C. Large-scale variations in the vegetation growing season and annual cycle of atmospheric $\mathrm{CO}_{2}$ at high northern latitudes from 1950 to 2011. Glob. Change Biol. 2013, 19, 3167-3183.

55. Barichivich, J.; Briffa, K.R.; Myneni, R.; Schrier, G.V.D.; Dorigo, W.; Tucker, C.J.; Osborn, T.J.; Melvin, T.M. Temperature and snow-mediated moisture controls of summer photosynthetic activity in northern terrestrial ecosystems between 1982 and 2011. Remote Sens. 2014, 6, 1390-1431.

56. Holben, B.N. Characteristics of maximum-value composite images from temporal AVHRR data. Int. J. Remote Sens. 1986, 7, 1417-1434.

57. Bai, X.; He, B.; Xing, M.; Li, X. Method for soil moisture retrieval in arid prairie using TerraSAR-X data. J. Appl. Remote Sens. 2015, doi:10.1117/1.JRS.9.096062.

58. Sheffield, J.; Wood, E.F. Global trends and variability in soil moisture and drought characteristics, 1950-2000, from observation-driven simulations of the terrestrial hydrologic cycle. J. Climate 2008, 21, 432-458.

59. GLDAS Noah Land Surface Model 14 Monthly $0.25 \times 0.25$ Degree Version 020. Available online: http://gcmd.nasa.gov/KeywordSearch/Metadata.do?Portal=NASA\&KeywordPath=Parameters|CL IMATE+INDICATORS\&OrigMetadataNode=GCMD\&EntryId=GES_DISC_GLDAS_NOAH02 5_M_V020\&MetadataView=Full\&MetadataType $=0 \& l b n o d e=$ mdlb1 (accessed on 14 July 2015).

60. Mann, H.B. Nonparametric tests against trend. Econometrica 1945, 13, 245-259.

61. Kendall, M. Rank Correlation Methods, 4th ed.; Griffin: London, UK, 1975.

62. Ichii, K.; Kondo, M.; Okabe, Y.; Ueyama, M.; Kobayashi, H.; Lee, S.J.; Saigusa, N.; Zhu, Z.; Myneni, R.B. Recent changes in terrestrial gross primary productivity in Asia from 1982 to 2011. Remote Sens. 2013, 5, 6043-6062.

63. Gocic, M.; Trajkovic, S. Analysis of changes in meteorological variables using Mann-Kendall and sen's slope estimator statistical tests in Serbia. Glob. Planet Change 2013, 100, 172-182.

64. Hamed, K.H. Trend detection in hydrologic data: The Mann-Kendall trend test under the scaling hypothesis. J. Hydrol .2008, 349, 350-363.

65. Long, D.; Shen, Y.; Sun, A.; Hong, Y.; Longuevergne, L.; Yang, Y.; Li, B.; Chen, L. Drought and flood monitoring for a large karst plateau in Southwest China using extended GRACE data. Remote Sens. Environ. 2014, 155, 145-160.

66. Abbas, S.; Nichol, J.E.; Qamer, F.M.; Xu, J. Characterization of drought development through remote sensing: A case study in central Yunnan, China. Remote Sens. 2014, 6, 4998-5018.

67. Wang, H.; Lin, H.; Liu, D. Remotely sensed drought index and its responses to meteorological drought in Southwest China. Remote Sens. Lett. 2014, 5, 413-422.

(C) 2015 by the authors; licensee MDPI, Basel, Switzerland. This article is an open access article distributed under the terms and conditions of the Creative Commons Attribution license (http://creativecommons.org/licenses/by/4.0/). 